\title{
Heterogeneity of soil surface temperature induced by xerophytic shrub in a revegetated desert ecosystem, northwestern China
}

\author{
Ya-Feng Zhang ${ }^{1,2}$, Xin-Ping Wang ${ }^{1, *}$, Yan-Xia PAn ${ }^{1}$, Rui Hu ${ }^{1,2}$ and HaO Zhang ${ }^{1,2}$ \\ ${ }^{1}$ Shapotou Desert Research and Experiment Station, Cold and Arid Regions Environmental and Engineering \\ Research Institute, Chinese Academy of Sciences, 320 Donggang West Road, Lanzhou 730000, China. \\ ${ }^{2}$ University of Chinese Academy of Sciences, Beijing 100049, China. \\ ${ }^{*}$ Corresponding author.e-mail: xpwang@lzb.ac.cn
}

\begin{abstract}
Variation characteristics of the soil surface temperature induced by shrub canopy greatly affects the nearsurface biological and biochemical processes in desert ecosystems. However, information regarding the effects of shrub upon the heterogeneity of soil surface temperature is scarce. Here we aimed to characterize the effects of shrub (Caragana korshinskii) canopy on the soil surface temperature heterogeneity at areas under shrub canopy and the neighbouring bare ground. Diurnal variations of soil surface temperature were measured at areas adjacent to the shrub base (ASB), beneath the midcanopy (BMC), and in the bare intershrub spaces (BIS) at the eastern, southern, western and northern aspects of shrub, respectively. Results indicated that diurnal mean soil surface temperature under the C. korshinskii canopy (ASB and BMC) was significantly lower than in the BIS, with the highest in the BIS, followed by the BMC and ASB. The diurnal maximum and diurnal variations of soil surface temperatures under canopy vary strongly with different aspects of shrub with the diurnal variation in solar altitude, which could be used as cues to detect safe sites for under-canopy biota. A significant empirical linear relationship was found between soil surface temperature and solar altitude, suggesting an empirical predicator that solar altitude can serve for soil surface temperature. Lower soil surface temperatures under the canopy than in the bare intershrub spaces imply that shrubs canopy play a role of 'cool islands' in the daytime in terms of soil surface temperature during hot summer months in the desert ecosystems characterized by a mosaic of sparse vegetation and bare ground.
\end{abstract}

\section{Introduction}

Arid and semi-arid ecosystems are often characterized by vegetation patchiness, arranging as a twophase mosaic of discontinuous vegetated patches surrounded by bare ground patches (Noy-Meir 1973; Rietkerk et al. 2004; Kéfi et al. 2007). Shrubs, known as 'fertile islands' (Garner and Steinberger 1989) in desert ecosystems, are characterized by higher soil fertility (Schlesinger et al. 1996) and less extreme microclimates (Vetaas 1992; Kidron 2010). Shrubs produce ecologically important microclimates (soil and air temperature, humidity, wind speed, solar radiation, soil evaporation, etc.) under their canopies in desert ecosystems (Vetaas 1992; Moro et al. 1997; Tracol et al. 2011), which greatly affects near-surface biological processes including seed germination (Valientebanuet and Ezcurra 1991; FrancoPizana et al. 1996; Mayor et al. 2007), soil seed banks (Price and Reichman 1987; Wang

Keywords. Soil surface temperature; heterogeneity; Caragana korshinskii; solar altitude; aspect. 
et al. 2010), seedling establishment, survival and growth (Franco and Nobel 1989; Moro et al. 1997; Ludwig et al. 2001; Schumacher et al. 2008; Griffith 2010), microbial activities (Goberna et al. 2007; Jia et al. 2010), root growth (Macduff et al. 1986), insects population dynamics (Shelef and Groner 2011; Carpintero et al. 2011), etc.

Sparse vegetation in desert ecosystems is usually interspersed by large patches of unshaded bare soil, which makes the desert landscape also a patchwork of sharply contrasting thermal environments (Boulet et al. 1999; Molles 2008). Desert soil temperatures are very high during the day, which often become lethal for seedlings of many species (Nobel 1984). Shrubs were reported to provide amelioration from high or even extreme surface temperature, characteristic of desert environments and further less soil evaporation at the microscale through a direct shading effect (Lowe and Hinds 1971; Nobel 1984; Hennessy et al. 1985; Souch and Souch 1993), by reducing solar radiation reaching the shaded area (Scholes and Archer 1997), which was regarded as the chief factor responsible for the nurse-plant effect in arid and semi-arid regions as suggested by Valientebanuet and Ezcurra (1991) and Kidron (2009). Moreover, sparse shrub vegetation was assumed to create considerable temporal and spatial variation in soil surface temperature regimes (Hinds and Rickard 1968; Pierson and Wight 1991; Humes et al. 1994; Castellanos et al. 1999). Soil surface temperature under plant canopy was reported to be lower than in the intershrub spaces in the daytime (e.g., Pierson and Wight 1991; Moro et al. 1997; El-Bana et al. 2002; Kidron 2009, 2010; Tracol et al. 2011), and to some extent, it is a supposable fact even to the nonprofessionals in this field. Only meagre information, however, exists regarding the extent to which shrubs alter the soil surface temperature. In particular, lacking are the studies on quantifying the heterogeneity of soil surface temperature at different aspects of shrub.

In this paper, we mainly aimed to characterize the spatial and temporal heterogeneity of soil surface temperature induced by $C$. korshinskii canopy by quantifying the surface temperature variation around it in terms of the distance from and the aspect to the canopy. Also, we discussed how soil surface temperature was influenced by the size and aspect of shrub canopy, as well as the potential maximum influencing values of space around the shrub canopy on the soil surface temperature. Finally, we constructed a linear regression model showing the relationship between soil surface temperature and solar altitude. The current research is expected to be meaningful for a better understanding of soil-vegetation-atmosphere processes at small scale. It also helps us to dig into the amelioration effects of revegetation efforts upon surface microclimate in restored desert ecosystems and its implications to some temperaturedependent near-surface biological and biochemical processes under shrub canopy.

\section{Materials and methods}

\subsection{Study area}

Measurements were conducted at Shapotou Desert Research and Experiment Station (SDRES) of Chinese Academy of Sciences $\left(37^{\circ} 32^{\prime} \mathrm{N}, 105^{\circ} 02^{\prime} \mathrm{E}\right.$, elevation of $1300 \mathrm{~m}$ above sea level), located at the southeastern fringe of the Tengger Desert in northwestern China. Mean annual precipitation is only $191 \mathrm{~mm}$ (1955-2005, SDRES) with $80 \%$ of rain occurring between July and September, and precipitation is the only source of soil water replenishment. Mean maximum air temperature is $24.7^{\circ} \mathrm{C}$ in July and the mean minimum is $-6.1^{\circ} \mathrm{C}$ in January. Maximum surface temperature can reach to $74^{\circ} \mathrm{C}$ during summer months. The potential evapotranspiration is as high as $2500 \mathrm{~mm}$ during the growing season, resulting in a large annual moisture deficit. The area is surrounded by relatively plain interdunes and free from any disturbances of grazing, fire, and wood chopping. The dune sand mainly consists of fine sand (0.05$0.25 \mathrm{~mm}$ ), and the clay content is about $0.2 \%$. The sand can thus be classified as Typic Psammaquents (Berndtsson et al. 1996).

To protect the Baotou-Lanzhou railway against encroaching sand dunes in the Shapotou area, a $16,000 \mathrm{~m}$ long (500 $\mathrm{m}$ width to the north and $200 \mathrm{~m}$ to the south) artificially revegetated protection system was established along the Baotou-Lanzhou railway after the revegetation efforts in the 1950s1980s, mainly by setting up straw checker boards in the moving sand soil and then planting xerophytic

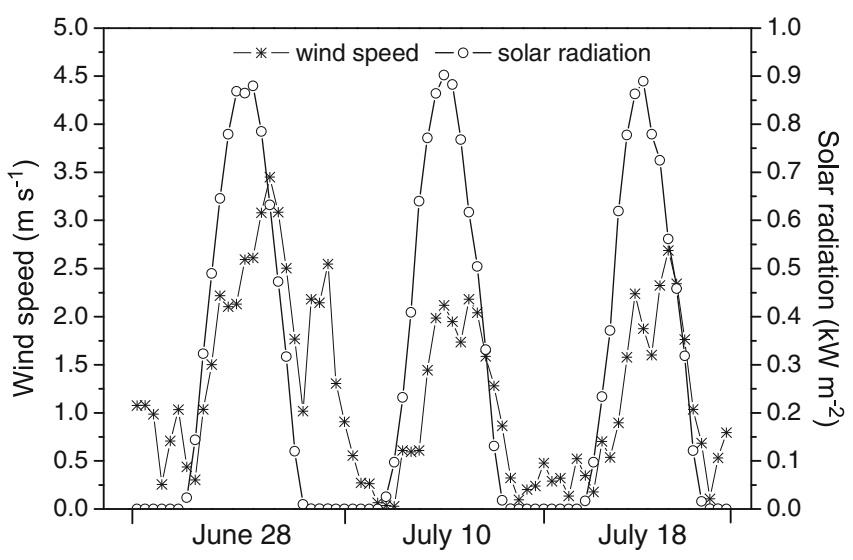

Figure 1. Solar radiation and wind speed at $2 \mathrm{~m}$ during the experimental period. 
shrub (such as C. korshinskii) and dwarf-shrub (such as Artemisia ordosica) species within them. The landscape in the revegetation area is characterized by a mosaic of sparse shrubs and herbs and the interspaces covered by biological soil crusts ( $\mathrm{Li}$ et al. 2003; Wang et al. 2007). Li et al. (2006) had a detailed description about the revegetation procedure.

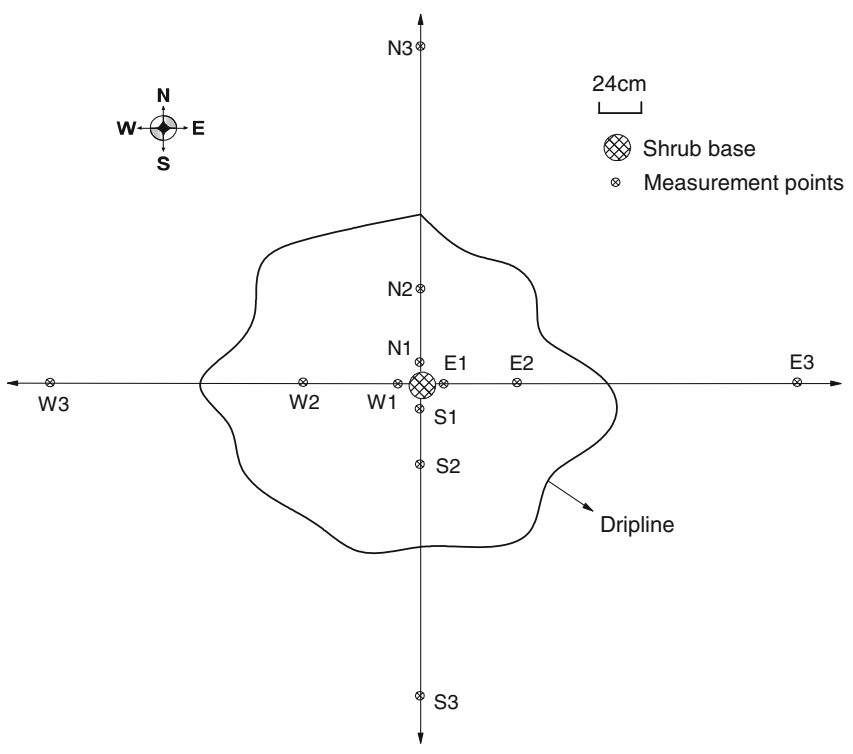

Figure 2. Sketch map of experimental set-up.

\subsection{Shrub description and selection}

C. korshinskii serves as one of the successful xerophytic shrubs in artificial revegetation along the Baotou-Lanzhou railway in the study area. C. korshinskii is a multi-stemmed deciduous perennial shrub and looks like an inverted cone. Leaves are pinnately compound and opposite or sub-opposite in arrangement and 6-10 cm long. Each pinna has 6 to 8 pairs of leaflets which are ovate in shape with 7-8 $\mathrm{mm}$ length and $2-5 \mathrm{~mm}$ width.

A robust and healthy adult shrub of $C$. korshinskii was chosen. The plant is $190 \mathrm{~cm}$ in height with a canopy size of 260 (east-west) $\times 240 \mathrm{~cm}$ (northsouth) and an LAI (leaf area index) of 0.95. It has 24 stems and the base area can be considered as a circle with a diameter of $15 \mathrm{~cm}$. The crown height is $150 \mathrm{~cm}$.

\subsection{Experimental design and field measurements}

Soil surface temperature was measured by a TC1100 Digital Thermocouple Thermometer (Line Seiki Co. Ltd., Tokyo, Japan) with a measurement range from 0 to $200^{\circ} \mathrm{C}$ and an accuracy of $\pm 0.1^{\circ} \mathrm{C}$. Thermometer connects Marlox thermocouple (Marlin manufacturing Corporation) to measure temperature. Three calm (mean wind speed less than $2 \mathrm{~m} \mathrm{~s}^{-1}$ during daytime) and cloudless days (June 28, July 10 and July 18, 2011), typical of summer days in study area, were chosen for

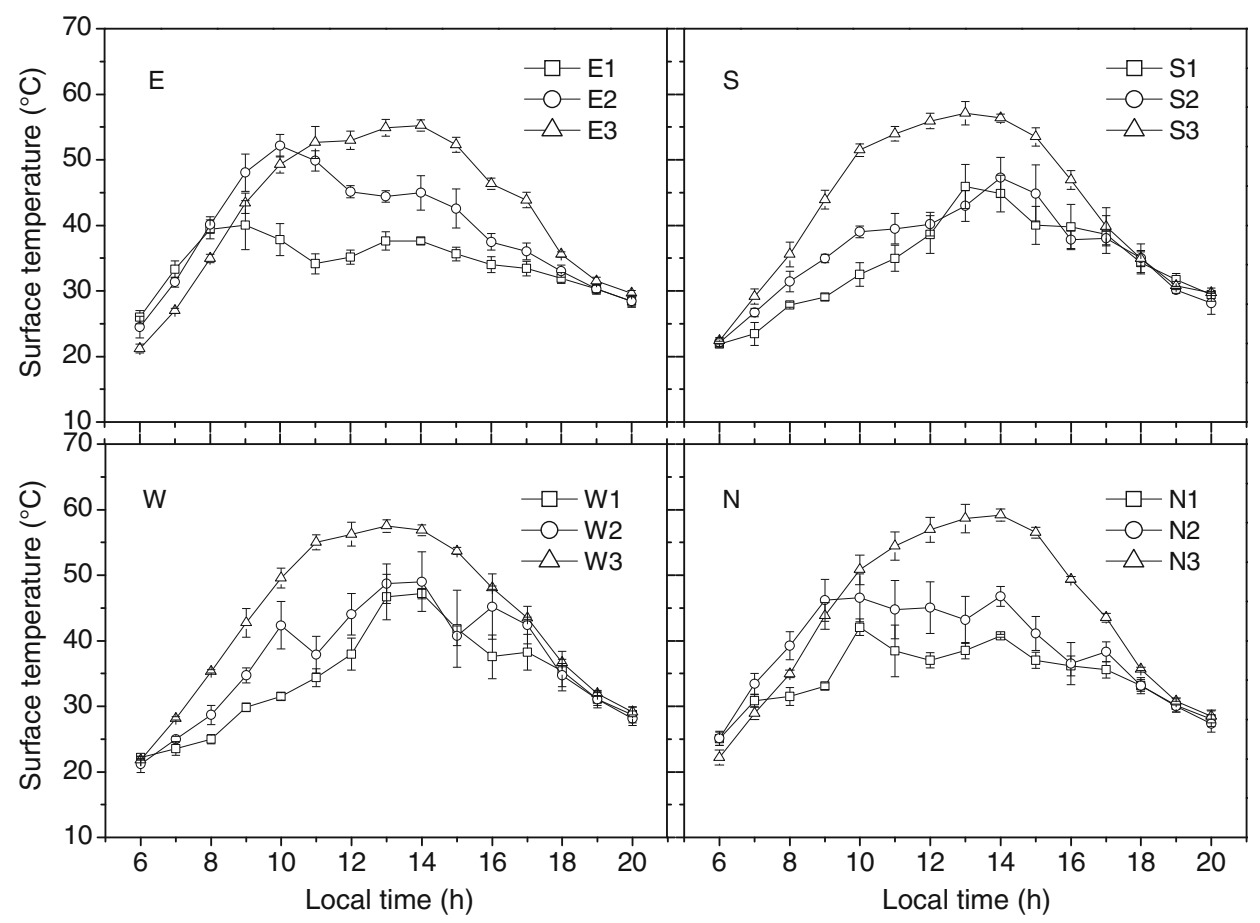

Figure 3. Average diurnal variation of surface temperature at each measurement point (as shown in figure 2) at the four shrub aspects (eastern: E; southern: S; western: W; northern: N), respectively. Bars represent the standard error. 
measurements to reduce the effects of clouds and wind on surface temperature (figure 1). Soil surface temperature measurements were taken in 1 hour interval from 06:00 to 20:00 local time (roughly from sunrise to sunset). All measurements can be done within 5 minutes each time.

Figure 2 displays the sketch top view of shrub and the measurement location distribution. Transects were placed radiating out in the four cardinal aspects (eastern: E; southern: S; western: W; and northern: N) from the shrub base to intershrub spaces for surface temperature measuring. In each aspect, three thermocouple probes were fixed at the soil surface with one adjacent to shrub base (ASB), one beneath the midcanopy (BMC), i.e., half the distance between shrub base and dripline, and one in the bare intershrub space (BIS). Measurement points include (1) E1, S1, W1 and N1 at the ASB; (2) E2, S2, W2 and N2 at the BMC; (3) E3, S3, $\mathrm{W} 3$ and N3 at the BIS. Among them, points in the BIS were completely free of shade. We took three readings at each point for each measurement and these readings were averaged for analysis. The perpendicular distances from the shrub base to the dripline were measured using a ruler rotating with an angle of $15^{\circ}$ starting from and finally ending to the eastern aspect as the axis of $0^{\circ}$. Through this, we can get 24 scatter dots to outline the shrub dripline and then determine the canopy vertical projection area of the shrub.

The Leaf Area Index (LAI) of the shrub, onesided leaf area per unit ground area, was estimated using a Li-Cor LAI-2000 Plant Canopy Analyzer (USA).

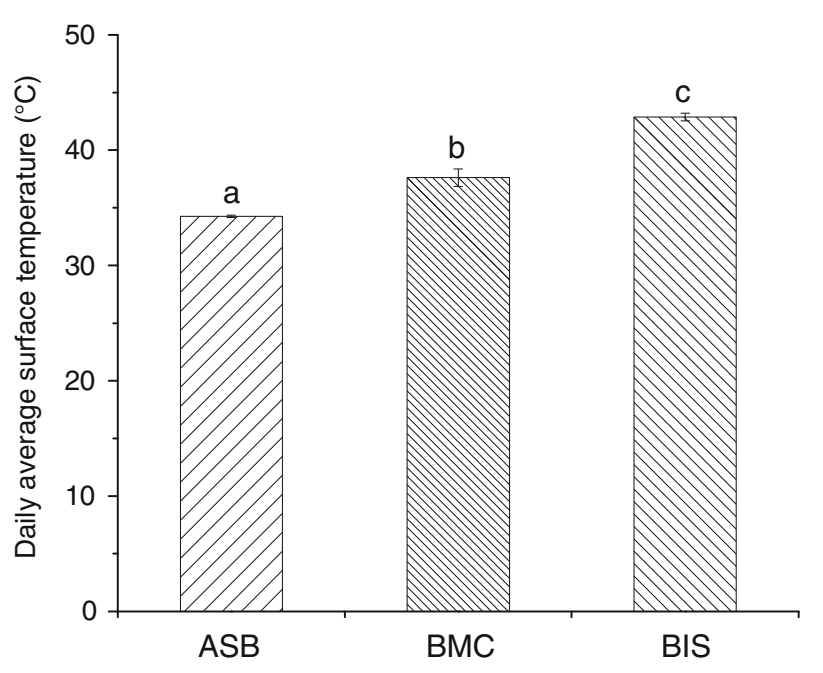

Figure 4. Comparison of the diurnal average surface temperatures (means $\pm \mathrm{SE}$ at four shrub aspects) that are adjacent to shrub base (ASB), beneath the mid-canopy (BMC) and in the bare intershrub spaces (BIS), respectively. Values with different letters $(\mathrm{a}, \mathrm{b}$ and $\mathrm{c}$ ) are significant at $\mathrm{P}<0.01$.
The soil is sandy soil covered by thin biological soil crusts at the soil surface. Soil moisture (0-6 cm) was measured by an NH2 Moisture Meter (Delta-T Devices Ltd., Cambridge, England) at areas ASB, BMC and in the BIS in a 2-hour interval during experiment period. We found the volumetric soil moisture was less than $0.01 \mathrm{VV}^{-1}$, and we thus considered the soil as dry and the soil moisture exerted a negligible effect on soil surface temperature.

Solar radiation and wind speed data at $2 \mathrm{~m}$ height above soil surface were derived from an automatic weather station (WS-STD1, UK).

\subsection{Statistical analyses}

We used one-way ANOVA to test the difference of diurnal mean soil surface temperature between the ASB, BMC and BIS and the difference of soil surface temperature at four aspects (eastern,

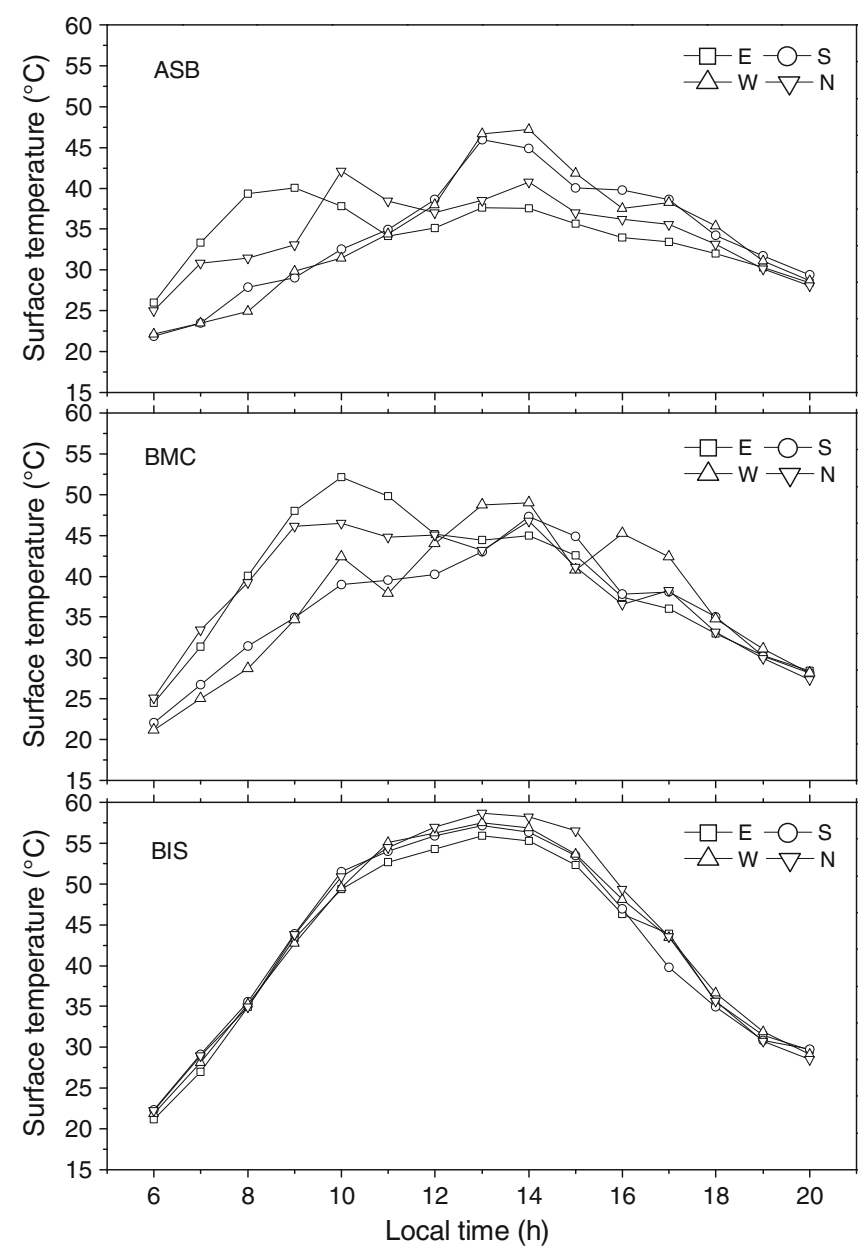

Figure 5. Diurnal variations of surface temperature adjacent to shrub base (ASB), beneath the mid-canopy (BMC) and in the bare intershrub space (BIS) in the eastern (E), southern (S), western (W) and northern (N) aspects of shrub, respectively. Data are measurements of three days averages. 
southern, western and northern) of shrub. Correlation analysis was employed to examine the relationship between soil surface temperature and solar altitude. All the ANOVA and correlation analyses were performed using the SPSS 16.0 statistical software (SPSS Inc., Chicago, USA).

\section{Results}

\subsection{Diurnal variations of soil surface temperature}

Figure 3 illustrates the average diurnal variations of soil surface temperature at each measurement point, respectively. Graphically, the diurnal mean variations of surface temperature in the BIS in the four aspects of shrub (E3, S3, W3 and N3) exclusively exhibited similar parabolic curves, with the diurnal maximum soil surface temperatures occurring around 13:00 (local time), and the lowest values around the sunrise and sunset. However, the diurnal curves of soil surface temperature at the ASB (E1, S1, W1 and N1) and BMC (E2, S2, W2 and N2) were generally lower and asymmetrically distributed comparing with that of BIS. Soil surface temperature started to differ among $\mathrm{ASB}, \mathrm{BMC}$ and BIS since sunrise and returned to convergence around sunset. Maximum soil surface temperatures occurred around 13:00 at the BIS, followed by the BMC and ASB but not always coincident at 13:00.

Table 1. Soil surface temperatures adjacent to shrub base (ASB), beneath the mid-canopy (BMC) and in the bare intershrub space (BIS) at the eastern (E), southern $(S)$, western (W) and northern (N) aspects of shrub, respectively.

\begin{tabular}{|c|c|c|c|c|c|c|c|c|c|c|c|c|}
\hline \multirow{3}{*}{$\begin{array}{l}\text { Time } \\
\text { (h) }\end{array}$} & \multicolumn{12}{|c|}{ Position } \\
\hline & \multicolumn{4}{|c|}{$\mathrm{ASB}$} & \multicolumn{4}{|c|}{$\mathrm{BMC}$} & \multicolumn{4}{|c|}{ BIS } \\
\hline & $\mathrm{E}$ & $\mathrm{S}$ & W & $\mathrm{N}$ & $\mathrm{E}$ & $\mathrm{S}$ & W & $\mathrm{N}$ & $\mathrm{E}$ & $\mathrm{S}$ & $\mathrm{W}$ & $\mathrm{N}$ \\
\hline \multirow[t]{2}{*}{6} & $26.0^{\mathrm{a}}$ & $21.9^{\mathrm{b}}$ & $22.2^{\mathrm{b}}$ & $25.0^{\mathrm{a}}$ & $24.5^{1}$ & $22.1^{1}$ & $21.2^{1}$ & $25.1^{1}$ & $21.2^{*}$ & $22.4^{*}$ & $21.8^{*}$ & $22.2^{*}$ \\
\hline & $(1.0)$ & $(0.4)$ & $(0.2)$ & $(1.0)$ & $(1.6)$ & $(0.6)$ & $(1.3)$ & $(1.1)$ & $(0.7)$ & $(0.5)$ & $(0.0)$ & $(1.2)$ \\
\hline \multirow[t]{2}{*}{7} & $33.3^{\mathrm{a}}$ & $23.5^{\mathrm{b}}$ & $23.5^{\mathrm{b}}$ & $30.9^{\mathrm{a}}$ & $31.3^{1}$ & $26.7^{2}$ & $25.0^{2}$ & $33.4^{1}$ & $27.0^{*}$ & $29.1^{*}$ & $28.2^{*}$ & $28.9^{*}$ \\
\hline & $(1.3)$ & $(1.8)$ & $(1.0)$ & $(0.9)$ & $(0.7)$ & $(0.7)$ & $(0.4)$ & $(1.6)$ & $(0.4)$ & $(1.2)$ & $(0.2)$ & $(0.9)$ \\
\hline \multirow[t]{2}{*}{8} & $39.4^{\mathrm{a}}$ & $27.9^{\mathrm{b}}$ & $25.0^{\mathrm{b}}$ & $31.5^{\mathrm{c}}$ & $40.1^{1}$ & $31.4^{2,3}$ & $28.7^{1,3}$ & $39.3^{1}$ & $34.9^{*}$ & $35.6^{*}$ & $35.3^{*}$ & $34.9^{*}$ \\
\hline & $(1.4)$ & $(0.4)$ & $(0.7)$ & $(1.4)$ & $(1.2)$ & $(1.6)$ & $(1.5)$ & $(2.2)$ & $(0.6)$ & $(1.9)$ & $(0.3)$ & $(0.6)$ \\
\hline \multirow[t]{2}{*}{9} & $40.1^{\mathrm{a}}$ & $29.1^{\mathrm{b}}$ & $29.8^{\mathrm{b}}$ & $33.1^{\mathrm{b}}$ & $48.0^{1}$ & $34.9^{2}$ & $34.7^{2}$ & $46.2^{1}$ & $43.4^{*}$ & $43.9^{*}$ & $42.7^{*}$ & $43.8^{*}$ \\
\hline & $(3.7)$ & $(0.5)$ & $(0.6)$ & $(0.5)$ & $(2.8)$ & $(0.7)$ & $(1.2)$ & $(3.2)$ & $(1.5)$ & $(1.4)$ & $(2.2)$ & $(2.0)$ \\
\hline \multirow[t]{2}{*}{10} & $37.8^{\mathrm{bc}}$ & $32.5^{\mathrm{ab}}$ & $31.5^{\mathrm{a}}$ & $42.1^{\mathrm{c}}$ & $52.1^{1}$ & $39.0^{2}$ & $42.3^{2}$ & $46.5^{1,2}$ & $49.3^{*}$ & $51.5^{*}$ & $49.6^{*}$ & $50.8^{*}$ \\
\hline & $(2.5)$ & $(1.8)$ & $(0.6)$ & $(1.2)$ & $(1.7)$ & $(0.9)$ & $(3.6)$ & $(3.7)$ & $(1.3)$ & $(1.0)$ & $(1.5)$ & $(2.2)$ \\
\hline \multirow[t]{2}{*}{11} & $34.1^{\mathrm{a}}$ & $35.0^{\mathrm{a}}$ & $34.4^{\mathrm{a}}$ & $38.5^{\mathrm{a}}$ & $49.8^{1}$ & $39.5^{2}$ & $37.9^{2}$ & $44.8^{1,2}$ & $52.7^{*}$ & $54.0^{*}$ & $55.0^{*}$ & $54.4^{*}$ \\
\hline & $(1.5)$ & $(2.0)$ & $(1.4)$ & $(3.9)$ & $(1.5)$ & $(2.3)$ & $(2.8)$ & $(4.5)$ & $(2.4)$ & $(1.1)$ & $(1.1)$ & $(2.1)$ \\
\hline \multirow[t]{2}{*}{12} & $35.2^{\mathrm{a}}$ & $38.6^{\mathrm{a}}$ & $38.0^{\mathrm{a}}$ & $37.0^{\mathrm{a}}$ & $45.1^{1}$ & $40.2^{1}$ & $44.0^{1}$ & $45.0^{1}$ & $52.9^{*}$ & $55.9^{*}$ & $56.3^{*}$ & $56.9^{*}$ \\
\hline & $(1.1)$ & $(2.9)$ & $(2.4)$ & $(1.2)$ & $(0.9)$ & $(1.8)$ & $(3.2)$ & $(3.9)$ & $(1.4)$ & $(1.2)$ & $(1.8)$ & (1.9) \\
\hline \multirow[t]{2}{*}{13} & $37.6^{\mathrm{a}}$ & $45.9^{\mathrm{b}}$ & $46.7^{\mathrm{b}}$ & $38.5^{\mathrm{a}}$ & $44.4^{1}$ & $43.0^{1}$ & $48.7^{1}$ & $43.2^{1}$ & $54.9^{*}$ & $57.1^{*}$ & $57.5^{*}$ & $58.7^{*}$ \\
\hline & $(1.4)$ & $(3.4)$ & $(3.5)$ & $(1.2)$ & $(0.9)$ & $(2.3)$ & $(3.0)$ & $(3.6)$ & $(1.3)$ & $(1.8)$ & $(1.0)$ & $(2.2)$ \\
\hline \multirow[t]{2}{*}{14} & $37.6^{\mathrm{a}}$ & $44.8^{\mathrm{bc}}$ & $47.2^{\mathrm{C}}$ & $40.8^{\mathrm{ab}}$ & $45.0^{1}$ & $47.3^{1}$ & $49.0^{1}$ & $46.8^{1}$ & $55.2^{*}$ & $56.3^{*}$ & $56.9^{*}$ & $59.2^{*}$ \\
\hline & $(0.5)$ & $(2.8)$ & $(0.8)$ & $(0.2)$ & $(2.6)$ & $(3.0)$ & $(4.6)$ & $(1.5)$ & $(0.9)$ & $(0.6)$ & $(0.8)$ & $(0.9)$ \\
\hline \multirow[t]{2}{*}{15} & $35.7^{\mathrm{a}}$ & $40.0^{\mathrm{a}}$ & $41.8^{\mathrm{a}}$ & $37.0^{\mathrm{a}}$ & $42.6^{1}$ & $44.9^{1}$ & $40.8^{1}$ & $41.1^{1}$ & $52.3^{*}$ & $53.5^{*}$ & $53.7^{*}$ & $56.5^{*}$ \\
\hline & $(1.0)$ & $(2.9)$ & $(5.9)$ & $(1.2)$ & $(3.0)$ & $(4.3)$ & $(1.5)$ & $(2.6)$ & $(1.2)$ & $(1.4)$ & $(0.5)$ & $(0.8)$ \\
\hline \multirow[t]{2}{*}{16} & $34.0^{\mathrm{a}}$ & $39.7^{\mathrm{a}}$ & $37.6^{\mathrm{a}}$ & $36.2^{\mathrm{a}}$ & $37.5^{1}$ & $37.8^{1}$ & $45.2^{1}$ & $36.5^{1}$ & $46.3^{*}$ & $46.9^{*}$ & $48.1^{*}$ & $49.4^{*}$ \\
\hline & $(1.2)$ & $(3.4)$ & $(3.3)$ & $(1.5)$ & $(1.2)$ & $(1.4)$ & $(5.0)$ & $(3.2)$ & $(0.9)$ & $(1.4)$ & $(0.2)$ & $(0.4)$ \\
\hline \multirow[t]{2}{*}{17} & $33.4^{\mathrm{a}}$ & $38.6^{\mathrm{a}}$ & $38.3^{\mathrm{a}}$ & $35.6^{\mathrm{a}}$ & $36.0^{1}$ & $38.0^{1,2}$ & $42.4^{1}$ & $38.3^{1,2}$ & $43.9^{*}$ & $39.8^{*}$ & $43.5^{*}$ & $43.5^{*}$ \\
\hline & $(1.1)$ & $(2.9)$ & $(2.7)$ & $(1.3)$ & $(1.3)$ & $(1.0)$ & $(2.9)$ & $(1.5)$ & $(1.2)$ & $(2.9)$ & $(0.2)$ & $(0.7)$ \\
\hline \multirow[t]{2}{*}{18} & $32.0^{\mathrm{a}}$ & $34.3^{\mathrm{a}}$ & $35.4^{\mathrm{a}}$ & $33.2^{\mathrm{a}}$ & $33.0^{1}$ & $35.0^{1}$ & $34.8^{1}$ & $33.2^{1}$ & $35.6^{*}$ & $35.0^{*}$ & $36.7^{*}$ & $35.7^{*}$ \\
\hline & $(0.8)$ & $(1.7)$ & $(3.0)$ & $(1.2)$ & $(0.9)$ & $(2.2)$ & $(1.7)$ & $(0.9)$ & $(0.4)$ & $(1.2)$ & $(0.5)$ & $(0.2)$ \\
\hline \multirow[t]{2}{*}{19} & $30.3^{\mathrm{a}}$ & $31.7^{\mathrm{a}}$ & $31.1^{\mathrm{a}}$ & $30.1^{\mathrm{a}}$ & $30.3^{1}$ & $30.2^{1}$ & $31.1^{1}$ & $30.0^{1}$ & $31.5^{*}$ & $30.8^{*}$ & $31.9^{*}$ & $30.8^{*}$ \\
\hline & $(0.8)$ & $(1.0)$ & $(1.3)$ & $(1.0)$ & $(0.6)$ & $(0.5)$ & $(0.9)$ & $(0.8)$ & $(0.6)$ & $(0.6)$ & $(0.3)$ & $(0.5)$ \\
\hline \multirow[t]{2}{*}{20} & $28.4^{\mathrm{a}}$ & $29.4^{\mathrm{a}}$ & $28.7^{\mathrm{a}}$ & $28.1^{\mathrm{a}}$ & $28.4^{1}$ & $28.1^{1}$ & $28.2^{1}$ & $27.4^{1}$ & $29.6^{*}$ & $29.7^{*}$ & $29.2^{*}$ & $28.5^{*}$ \\
\hline & $(0.9)$ & $(1.0)$ & $(1.2)$ & $(1.2)$ & $(0.8)$ & $(1.8)$ & $(1.1)$ & $(1.3)$ & $(0.4)$ & $(0.1)$ & $(0.7)$ & $(1.0)$ \\
\hline
\end{tabular}

Value in parentheses presents standard error. $\mathrm{n}=3$.

Values with different letters $(\mathrm{a}, \mathrm{b}$ and $\mathrm{c})$ are significant at the ABS at $\mathrm{P}<0.01$; values with different numbers $(1,2$ and 3 ) are significant at the $\mathrm{BMC}$ at $\mathrm{P}<0.01$; values with asterisk $(*)$ are not significant at $\mathrm{P}<0.05$ in the BIS. 
Differences in means of diurnal soil surface temperature were highly significant $(\mathrm{P}<0.01)$ among $\mathrm{ASB}, \mathrm{BMC}$ and BIS, as shown in figure 4. Mean soil surface temperature was $42.9^{\circ} \mathrm{C}$ at the BIS and decreased by $5.3^{\circ} \mathrm{C}$ towards $\mathrm{BMC}\left(37.6^{\circ} \mathrm{C}\right)$, and by $8.6^{\circ} \mathrm{C}$ towards $\operatorname{ASB}\left(34.3^{\circ} \mathrm{C}\right)$. In particular, the differences of surface temperature between $\mathrm{ASB}, \mathrm{BMC}$ and BIS were the most pronounced around local noon time. For example, the mean soil surface temperature at the ASB, BMC and BIS approached $37.2,43.6$ and $55.5^{\circ} \mathrm{C}$ at $13: 00$, i.e., there was a difference of $18.3^{\circ} \mathrm{C}$ between BIS and $\mathrm{ASB}$, and an $11.9^{\circ} \mathrm{C}$ difference between BIS and BMC.

\subsection{Effects of shrub aspects on soil surface temperature}

Generally, as shown in figure 5 and table 1, the soil surface temperatures under shrub canopy (ASB and BMC) were larger in the eastern and northern aspects than in the southern and western aspects before 12:00, but the tendency was opposite after 12:00. Occasionally, significant differences of soil surface temperature were found among different shrub aspects at the ASB and BMC (table 1). For example, at 09:00 at the ASB, soil surface temperature at the eastern aspect was $11.0,10.3$ and $8.0^{\circ} \mathrm{C}$ higher $(\mathrm{P}<0.01)$ than at the southern, western and northern aspects, respectively, while at 14:00, soil surface temperature at the eastern aspect was $7.2,9.6$ and $3.2^{\circ} \mathrm{C}$ lower than at the southern, western and northern aspects, respectively. However, in the BIS, no significant difference of soil surface temperature was found at the four aspects around shrub during the observation periods. Although, the differences in soil surface temperature existed between the four aspects at a specific time of the day, no significant differences between the mean of the diurnal surface temperatures were found between the four aspects of shrub. The shading effect of canopy was observed more pronounced at the $\mathrm{ASB}$ and $\mathrm{BMC}$ at the western aspect of the shrub in the morning and that was the case for the eastern aspect of shrub in the afternoon, because area under canopy in the eastern aspect of shrub received more solar radiation than in the western aspect in the morning but less in the afternoon, it varied with the diurnal variation of solar altitude. Moreover, time difference of the diurnal maximum soil surface temperature existed under canopy at different aspects. For example, at the ASB, soil surface temperature at the eastern aspect reached its peak around 09:00 and then decreased, while it happened around 14:00 at the western aspect, i.e., there was a 5 hours delay of the diurnal maximum soil surface temperature occurring at
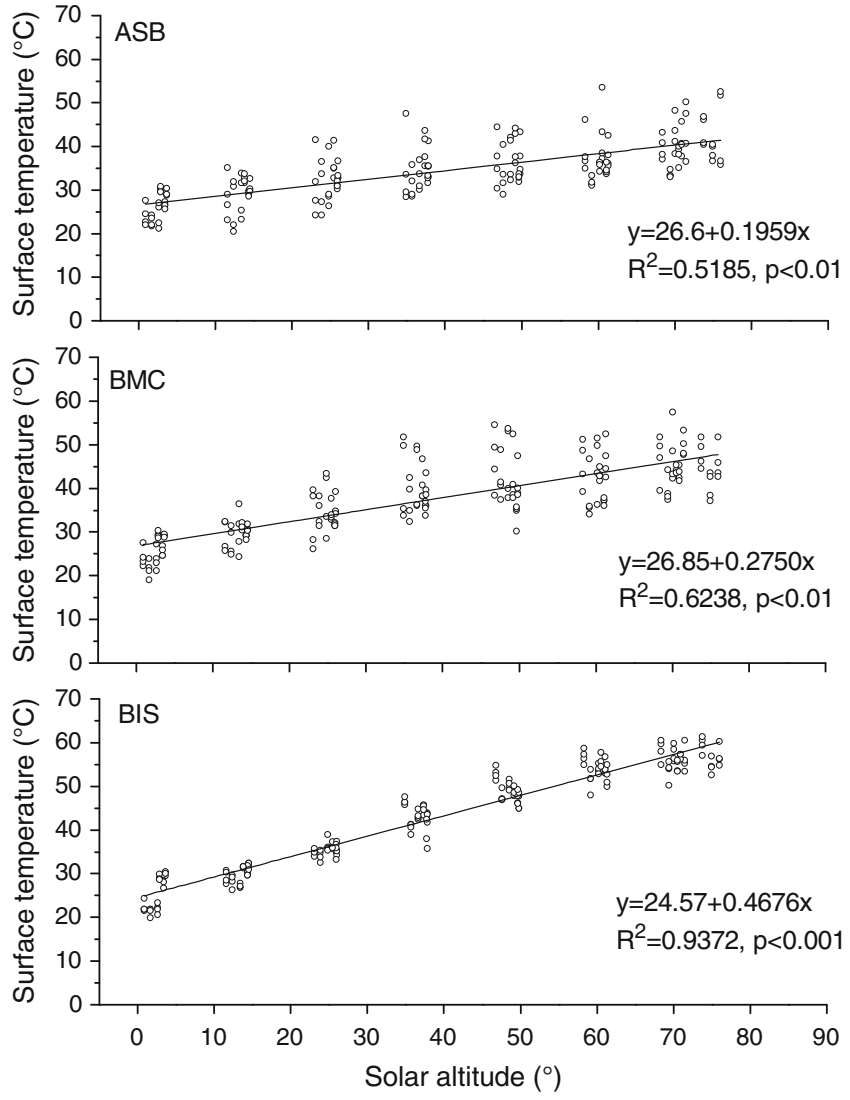

Figure 6. Relationships between surface temperature and solar altitude adjacent to shrub base (ASB), beneath the mid-canopy (BMC) and in the bare intershrub spaces (BIS), respectively.

western aspect of shrub comparing with that at eastern aspect. Similar phenomenon was also evidenced at the BMC.

\subsection{Statistical relationship between surface temperature and solar altitude}

Figure 6 illustrates the statistical relationship between soil surface temperature and solar altitude. Soil surface temperature increased with the increasing of solar altitude and a well correlated linear relationship was found between them with a coefficient of determination of $0.9372,0.6238$ and 0.5185 for BIS, BMC and ABS, respectively. Soil surface temperature under canopy (ABS and BMC) had a slower increase as solar altitude increased than in the BIS.

\section{Discussion and conclusions}

In this study, a notable shrub effect on soil surface temperature variations was identified. Soil surface temperatures under the canopy (ASB and BMC) of C. korshinskii were significantly $(\mathrm{P}<0.01)$ lower 
than in the BIS. The difference of diurnal mean surface temperature between BIS and ASB was $8.6^{\circ} \mathrm{C}$ and it can be as high as $18.3^{\circ} \mathrm{C}$ at $13: 00$, and the counterparts between BIS and BMC were $5.3^{\circ} \mathrm{C}$ and $11.9^{\circ} \mathrm{C}$ at $13: 00$, respectively. In addition, diurnally, soil surface temperature under shrub canopy showed less variability as compared to the BIS, i.e., shrub canopy buffers the diurnal variability of soil surface temperature. We thus concluded that in addition to the well known role of 'fertile islands' (Garner and Steinberger 1989), shrubs also play a notable role of 'cool islands' in the daytime in a narrow sense. In terms of soil surface temperature, desert landscape can also be described as a mosaic of cool islands under shrub canopies and the warmer islands in the bare intershrub spaces. Note that the 'cool islands' effect under shrub canopies works only in the daytime, nighttime temperatures under the canopies may be a little higher than in the intershrub spaces (Kidron 2010; D'Odorico et al. 2010). Our study area experienced a long term artificial revegetation, which transformed the former landscape with bare and homogeneous moving sand dunes into the landscape characterized by a mosaic of the sparse shrubs and herbs and the interspaces covered by biological soil crusts (e.g., Li et al. 2006). There is a substantial increase in biodiversity and a great improvement of soil fertility after long term revegetation ( $\mathrm{Li}$ et al. 2004). C. korshinskii, a nitrogen-fixing legume, showed good performance in the revegetation and is regarded as one of the chief sand-fixing shrubs in desert areas. Our results showed that the shrub C. korshinskii, serving as a natural barrier against the external harsh thermal conditions, provided amelioration from high soil surface temperature especially at midday and may further greatly modify the microhabitat under the canopies. Thus, this also suggests an amelioration effect of revegetation efforts upon surface microclimate in terms of soil temperature around plants mainly by planting xerophytic shrubs into the straw checker boards in Shapotou area where the maximum surface temperature of bare sandy soil can be as high as $74^{\circ} \mathrm{C}$ in summer months (Wang et al. 2002). 'Cool islands' effect induced by shrubs may have been playing and are expected to play a positive role in the succession of the revegetated ecosystem of study area.

Our experimental results, combined with previous studies (e.g., Pierson and Wight 1991; Tielbörger and Kadmon 1995; Retana and Cerda 2000; Hastwell and Facelli 2003; Armas and Pugnaire 2005; Kidron 2009, 2010; Celaya-Michel and Castellanos-Villegas 2011; Zhou et al. 2011; Kidron and Vonshak 2012), imply that the differential degrees of soil temperature induced by shrub canopy may strongly affect some of the temperature-dependent near-surface biochemical and biological processes, including in differential soil moisture regime and soil evaporation, different rates of soil nitrogen mineralization, seed germination and annuals establishment, microbial activities and insect dynamics, with important implications for the formation and expansion of fertile islands in arid landscapes. Kidron (2009, 2010) indicated that, concerning the fertile islands in arid and semi-arid zones, the primary and principal role of shrubs was in altering the microclimate rather than in improving the nutrient status of the soil. Protected from direct sun and wind, shrubs are responsible for lower soil temperature, which is likely to be highly correlated with conditions such as reduced solar radiation and soil evaporation and the longer wetness duration following rain and higher relative humidity under shrubs (Kidron 2010; Kidron and Vonshak 2012). Therein, as was found in the Negev Desert, the daylight wetness duration of habitats covered with microbiotic crusts both under and adjacent to shrub, varying with aspects of shrub, further affected the photosynthetic activity and hence biomass of microbiotic crusts and a good positive linear relation was found between them (Kidron and Vonshak 2012). In the desert, soil temperature and soil water are the two most crucial factors governing seed germination (Forcella et al. 2000). In fact, the wetter and mild surface soils existing under the shrub canopy may facilitate seed germination and vegetation establishment and growth, while the drier and parched soil in the severe areas of interspaces may prevent these processes (Hastwell and Facelli 2003; Armas and Pugnaire 2005). Wang et al. (2010) found that forb seeds were more abundant under $C$. korshinskii than in the interspaces in the study area, which, according to our results, may suggest a higher seed germination rate and further more surviving plants beneath shrubs than in the intershrub spaces. In fact, higher density of annuals is always found under shrub canopy, as reported by Tielbörger and Kadmon (1995) in the Negev Desert. Moreover, 'cool islands' in deserts are often favourable for higher microbial activities under shrub canopy and would further enhance microbially driven ecosystem processes (Goberna et al. 2007), which is associated with higher rates of soil carbon and nitrogen mineralization and organic matter decomposition, etc. For example, Jia et al. (2010) noticed that $C$. korshinskii promotes the soil microbial biomass and activity. Zhou et al. (2011) found a significantly higher soil carbon mineralization potential beneath $C$. korshinskii in the study area. Celaya-Michel and Castellanos-Villegas (2011) reported a higher rate of nitrogen mineralization under the canopy of shrubs, particularly under nitrogen-fixing legumes, compared to open 
interspaces in arid and semi-arid ecosystems. Additionally, shading by shrubs provides shelter for insects, reptiles and other organisms in hot summer months. For instance, by studying ants as bioindicators in the Tabernas Desert, Carpintero et al. (2011) reported higher densities of individuals and species richness under shrub canopy than in the interspaces, and pointed out that lower soil temperature beneath canopy may be the main factor. The soil surface temperature measurements made in the present study also showed that aspect of shrub strongly affected soil surface temperature heterogeneity around the shrub. The diurnal maximum temperatures and the diurnal variations of surface temperature at the ASB and BMC varied strongly with different aspects of shrub (figure 5). Diurnal variation of soil surface temperature are often more important to plants and animals than the average temperature (Joyce 2009). These results suggest that maximum temperatures or diurnal temperature variations can be used as cues to detect safe sites for the biota under the canopy. For example, Retana and Cerda (2000) noticed that ant communities track spatial and temporal variability in the thermal environment and reached the similar conclusions as above Carpintero et al. (2011). Accordingly, the amelioration of the thermal environment produced by the patchy shrubs plays an important role in the under-canopy biota in desert ecosystems.

The lower under-canopy soil temperatures could mainly be explained by shading of shrub canopy which attenuates the solar radiation reaching the shaded soil surface, as suggested by e.g., Kidron (2010). Shading by shrub canopies might be especially important in deserts where the solar radiation is strong and the canopy cover is often low (Zou et al. 2010). Soil moisture $\left(<0.01 \mathrm{VV}^{-1}\right)$ was assumed to exert a negligible effect on the heterogeneity of soil surface temperature in the present study, because the measurements of surface temperature were taken when the soil surface was dry, which removed the influences of soil moisture. The diurnal behaviour of soil surface temperature would be rather complex when the surface is in wet conditions, since more of the solar radiation reaching the soil would be applied to evaporate soil water but not mostly to heat the soil resulting in less sensible heat and a smaller temperature increase than in dry conditions (Minnis et al. 1997). In the study area, the annual mean precipitation is only $191 \mathrm{~mm}$ and in the most time of the year the soil surface is in dry conditions, and the three days we chose for measurements are of typical in the hot summer months. Thus, our results are of representative and meaningful.

The surface temperature heterogeneity beneath shrub canopy was attributed to the uneven shading of shrub canopy over time in the daytime, depending on the canopy architecture and the diurnal variations in solar altitude. Solar radiation was greatly attenuated through shrub canopy (Thomas and Kliebenstein 2000; Forseth et al. 2001), and the size and shape of shade is determined both by canopy architecture and the diurnal variation of solar altitude (Kuuluvainen and Pukkala 1989; Zou et al. 2010; Raz-Yaseef et al. 2010). Thus, shading by shrub is dynamic over time, which also would generate a rather complex variability of soil surface temperature around shrub. In the present study, for example, partial shading was experienced by the habitats at the western aspect during early morning and eastern aspect during the late afternoon, which caused higher soil surface temperatures at the eastern aspect in the morning and lower values in the afternoon compared with that at the western aspect. At 08:00 and 18:00, a warming can be seen on sunward side of the shrub, and a long light shadow is obvious on the lee side. At 14:00, shadow is much smaller, but the shading is intense. Time difference of the diurnal maximum soil surface temperature at different aspects beneath the shrub canopy (figure 5) is also attributable to the dynamic shading. We thus assume that there exists a dynamic shading area around shrub varying with the variation of solar altitude that influences soil surface temperature. Even though, theoretically, we can predict the shading area of canopy according to the solar altitude and precisely measured shrub canopy geometry, it is, however, hard to precisely predict soil surface temperature around shrubs, because surface temperature reveals the dynamic equilibrium between incoming and outgoing energy flux (Garratt 1992), it is a function of soil, vegetation and atmospheric variables which vary in space, plus the shading of canopy is dynamic and uneven due to complex canopy architecture.

Moreover, our results indicated that the diurnal variations of solar altitude correlated well with soil surface temperature, and empirically, soil surface temperature linearly increased as solar altitude increased (figure 6). The correlation of soil surface temperature and solar altitude was not so strong for ABS and BMC as for BIS due to the variations of soil surface temperature owing to varying canopy shading in the ABS and BMC but not in the BIS at different aspects of shrub. Although there is no direct causation between solar altitude and soil surface temperature, a functional relationship between them can be proposed. It should be noted that solar altitude influence soil surface temperature in an indirect way through altering the intensity of solar radiation striking soil surfaces over time. In addition, empirical formulas in figure 6 showed that soil surface temperature 
beneath the shrub canopy (ABS and BMC) had a slower increase as solar altitude increased than in the BIS. The statistical relationship between solar altitude and soil surface temperature implies that solar altitude could be used as a predicator of soil surface temperature, especially for that of bare soil.

\section{Acknowledgements}

This study was supported by the 100-talents Program of the Chinese Academy of Sciences and the National Natural Science Foundation of China (41201085).

\section{References}

Armas C and Pugnaire F I 2005 Plant interactions govern population dynamics in a semi-arid plant community; J. Ecol. 93 978-989.

Berndtsson R, Nodomi K, Yasuda H, Persson T, Chen H S and Jinno K 1996 Soil water and temperature patterns in an arid desert dune sand; J. Hydrol. 185 221-240.

Boulet G, Chehbouni A, Braud I and Vauclin M 1999 Mosaic versus dual source approaches for modelling the surface energy balance of a semi-arid land; Hydrol. Earth Syst. Sci. 3 247-258.

Carpintero S, Reyes-Lopez J and Luque G M 2011 Ant community structure under Retama sphaerocarpa shrubs in a semi-arid environment; Entomol. Sci. 14 147-153.

Castellanos A E, Tinoco-Ojanguren C and Molina-Freaner F 1999 Microenvironmental heterogeneity and space utilization by desert vines within their host trees; Ann. Bot. London 84 145-153.

Celaya-Michel H and Castellanos-Villegas A E 2011 Nitrogen mineralization on arid and semi-arid land soil; Terra Latinoamericana $29343-356$.

D'Odorico P, Fuentes J D, Pockman W T, Collins S L, He Y, Medeiros J S, Dewekker S and Litvak M E 2010 Positive feedback between microclimate and shrub encroachment in the northern Chihuahuan desert; Ecosphere 1(6) 1-11.

El-Bana M I, Nijs I and Kockelbergh F 2002 Microenvironmental and vegetational heterogeneity induced by phytogenic nebkhas in an arid coastal ecosystem; Plant Soil $247283-293$.

Forcella F, Arnold R L B, Sanchez R and Ghersa C M 2000 Modeling seedling emergence; Field Crop. Res. 67 123-139.

Forseth I N, Wait D A and Casper B B 2001 Shading by shrubs in a desert system reduces the physiological and demographic performance of an associated herbaceous perennial; J. Ecol. 89 670-680.

Franco A C and Nobel P S 1989 Effect of nurse plants on the microhabitat and growth of Cacti; J. Ecol. 77 870-886.

FrancoPizana J G, Fulbright $\mathrm{T}$ E, Gardiner D $\mathrm{T}$ and Tipton A R 1996 Shrub emergence and seedling growth in microenvironments created by Prosopis glandulosa; J. Veg. Sci. 7 257-264.

Garner W and Steinberger Y 1989 A proposed mechanism for the formation of "Fertile Island" in the desert ecosystem; J. Arid Environ. 16 257-262.

Garratt J R 1992 The atmospheric boundary layer; Cambridge University Press, Cambridge, UK.

Goberna M, Pascual J A, Garcia C and Sanchez J 2007 Do plant clumps constitute microbial hotspots in semiarid
Mediterranean patchy landscapes; Soil Biol. Biochem. 39 1047-1054.

Griffith A B 2010 Positive effects of native shrubs on Bromus tectorum demography; Ecology 91 141-154.

Hastwell G T and Facelli J M 2003 Differing effects of shade-induced facilitation on growth and survival during the establishment of a chenopod shrub; J. Ecol. 91(6) 941-950.

Hennessy J T, Gibbens R P, Tromble J M and Cardenas M 1985 Mesquite (Prosopis grandulosa Torr.) dunes and interdunes in southern New Mexico: A study of soil properties and soil water relations; J. Arid Environ. $927-38$.

Hinds W T and Rickard W H 1968 Soil temperatures near a desert steppe shrub; Northwest Sci. 42 5-8.

Humes K S, Kustas W P, Moran M S, Nichols W D and Weltz M A 1994 Variability of emissivity and surfacetemperature over a sparsely vegetated surface; Water Resour. Res. 30 1299-1310.

Jia G M, Liu B R, Wang G and Zhang B L 2010 The microbial biomass and activity in soil with shrub (Caragana korshinskii $K$.) plantation in the semi-arid loess plateau in China; Eur. J. Soil Biol. 46 6-10.

Joyce A Q 2009 Desert biomes (Greenwood Guides to Biomes of the World); Greenwood Press, Westport, Connecticut, $5 \mathrm{p}$.

Kéfi S, Rietkerk M, Alados C L, Pueyo Y, Papanastasis V P, ElAich A and de Ruiter P C 2007 Spatial vegetation patterns and imminent desertification in Mediterranean arid ecosystems; Nature 449 213-215.

Kidron G J 2009 The effect of shrub canopy upon surface temperatures and evaporation in the Negev Desert; Earth Surf. Proc. Land 34 123-132.

Kidron G J 2010 Under-canopy microclimate within sand dunes in the Negev Desert; J. Hydrol. 392 201-210.

Kidron G J and Vonshak A 2012 The use of microbiotic crusts as biomarkers for ponding, subsurface flow and soil moisture content and duration; Geoderma 181 56-64.

Kuuluvainen T and Pukkala T 1989 Simulation of withintree and between-tree shading of direct-radiation in a forest canopy-effect of crown shape and sun elevation; Ecol. Model. 49 89-100.

Li X R, Zhou H Y, Wang X P, Zhu Y G and O'Conner P J 2003 The effects of sand stabilization and revegetation on cryptogam species diversity and soil fertility in the Tengger Desert, Northern China; Plant Soil 251 $237-245$.

Li X R, Xiao H L, Zhang J G and Wang X P 2004 Longterm ecosystem effects of sand-binding vegetation in the Tengger Desert, northern China; Restor. Ecol. 12(3) 376-390.

Li X R, Xiao H L, He M Z and Zhang J G 2006 Sand barriers of straw checkerboards for habitat restoration in extremely arid desert regions; Ecol. Eng. 28 149-157.

Lowe C H and Hinds D S 1971 Effect of paloverde (Cercidium) trees on the radiation flux at ground level in the Sonoran Desert in winter; Ecol. 52(5) 916-922.

Ludwig F, de Kroon H, Prins H H T and Berendse F 2001 Effects of nutrients and shade on tree-grass interactions in an East African savanna; J. Veg. Sci. 12 $579-588$.

Macduff J H, Wild A, Hopper M J and Dhanoa M S 1986 Effects of temperature on parameters of root-growth relevant to nutrient-uptake - measurements on oilseed rape and barley grown in flowing nutrient solution; Plant Soil $94321-332$.

Mayor M D, Boo R M, Pelaez D V, Elia O R and Tomas M A 2007 Influence of shrub cover on germination, dormancy and viability of buried and unburied seeds of 
Piptochaetium napostaense (Speg.) Hackel; J. Arid Environ. 68 509-521.

Minnis P, Mayor S, Smith W L and Young D F 1997 Asymmetry in the diurnal variation of surface albedo; IEEE T. Geosci. Remote 35 879-891.

Molles MC Jr 2008 Ecology: Concepts and applications; 4th edn (New York: McGraw-Hill), pp. 82-86.

Moro M J, Pugnaire F I, Haase P and Puigdefabregas J 1997 Effect of the canopy of Retama sphaerocarpa on its understorey in a semiarid environment; Funct. Ecol. 11 425-431.

Nobel P S 1984 Extreme temperatures and thermal tolerances for seedlings of desert succulents; Oecologia 62 310-317.

Noy-Meir I 1973 Desert ecosystems: environment and producers; Ann. Rev. Ecol. Syst. 4 25-51.

Pierson F B and Wight J R 1991 Variability of nearsurface soil-temperature on sagebrush rangeland; $J$. Range Manag. 44 491-497.

Price M V and Reichman O J 1987 Distribution of seeds in sonoran desert soils: Implications for deteromyid rodent foraging; Ecology 68 1797-1811.

Raz-Yaseef N, Rotenberg E and Yakir D 2010 Effects of spatial variations in soil evaporation caused by tree shading on water flux partitioning in a semi-arid pine forest; $\mathrm{Agr}$. Forest Meteorol. 150 454-462.

Retana J and Cerda X 2000 Patterns of diversity and composition of Mediterranean ground ant communities tracking spatial and temporal variability in the thermal environment; Oecologia 123(3) 436-444.

Rietkerk M, Dekker S C, de Ruiter P C and van de Koppel J 2004 Self-organized patchiness and catastrophic shifts in ecosystems; Science 305 1926-1929.

Schlesinger W H, Raikes J A, Hartley A E and Cross A E 1996 On the spatial pattern of soil nutrients in desert ecosystems; Ecology 77 364-374.

Scholes R J and Archer S R 1997 Tree-grass interactions in savannas; Ann. Rev. Ecol. Syst. 28 517-544.

Schumacher E, Kueffer C, Tobler M, Gmur V, Edwards P J and Dietz H 2008 Influence of drought and shade on seedling growth of native and invasive trees in the Seychelles; Biotropica 40 543-549.
Shelef O and Groner E 2011 Linking landscape and species: Effect of shrubs on patch preference of beetles in arid and semi-arid ecosystems; J. Arid Environ. 75 960-967.

Souch C A and Souch A 1993 The effect of trees on summertime below canopy urban climates: A case study Bloomington, Indiana; J. Arboric. 19 303-311.

Thomas W J and Kliebenstein H 2000 Canopy architecture, light extinction and self-shading of a prairie grass, andropogon gerardii; Am. Midl. Nat. 144 51-65.

Tielbörger K and Kadmon R 1995 Effect of shrubs on emergence, survival and fecundity of four coexisting annual species in a sandy desert ecosystem; Ecoscience $\mathbf{2}$ $141-147$.

Tracol Y, Gutierrez J R and Squeo F A 2011 Plant area index and microclimate underneath shrub species from a Chilean semiarid community; J. Arid Environ. $\mathbf{7 5}$ $1-6$.

Valientebanuet A and Ezcurra E 1991 Shade as a cause of the association between the cactus neobuxbaumia-tetetzo and the nurse plant mimosa-luisana in the Tehuacan valley, Mexico; J. Ecol. 79 961-971.

Vetaas O R 1992 Micro-site effects of trees and shrubs in dry savannas; J. Veg. Sci. 3 337-344.

Wang X P, Li X R, Xiao H L, Berndtsson R and Pan Y X 2007 Effects of surface characteristics on infiltration patterns in an arid shrub desert; Hydrol. Process. 21 $72-79$

Wang X P, Li X R, Zhang J G, Zhou H Y and Berndtsson R 2002 Variation of soil temperature and thermal diffusivity in vegetated and bare sand dunes in arid desert region; J. Desert Res. 22 344-349 (in Chinese).

Wang X P, Wang Z N, Cui Y and Pan Y X 2010 Variation in soil seed banks composition at the desert microhabitats of Caragana korshinskii shrubs; Arid Land Res. Manag. $24238-252$.

Zou C B, Royer P D and Breshears D D 2010 Densitydependent shading patterns by Sonoran saguaros; J. Arid Environ. 74 156-158.

Zhou Y Y, Jia X H, Zhao X, Chen G X, Gao Y H and Wu P 2011 Soil carbon mineralization potential under different configuration of vegetation; Chinese J. Ecology $302422-2448$ (in Chinese). 